\title{
Variations
}

Variations Revue internationale de théorie critique

\section{Échos et résonances}

Éditorial

\section{(2) OpenEdition}

\section{Journals}

Édition électronique

URL : https://journals.openedition.org/variations/2055

DOI : 10.4000/variations.2055

ISSN : 1968-3960

\section{Éditeur}

Les amis de Variations

Référence électronique

"Échos et résonances 》, Variations [En ligne], 24 | 2021, mis en ligne le 03 juillet 2021, consulté le 07 juillet 2021. URL : http://journals.openedition.org/variations/2055 ; DOI : https://doi.org/10.4000/ variations.2055

Ce document a été généré automatiquement le 7 juillet 2021.

Les ami•e•s de Variations 


\section{Échos et résonances}

\section{Éditorial}

1 La présente livraison de la revue Variations s'ouvre sur un débat américain contemporain à propos de la possibilité de remettre à jour le Manifeste communiste de Marx et Engels, en décalage avec les traditions du marxisme traditionnel. Nous espérons ainsi attiser curiosité, étonnement et attention. Pour continuer sur cette lancée, une deuxième partie propose une ribambelle de textes et de traductions inédites (Adorno, Backhaus, Buck-Morss, Horkheimer et Korsch) qui auscultent, chacun à leur manière, les échos du marxisme à la Théorie critique.

2 Depuis sa création, la revue Variations explore, en effet, les textes critiques qui explorent les voies et proposent les interprétations les plus originales, à l'écart bien souvent des traditions historiques les plus connues. Et cela concerne en particulier les auteurs les plus exposés, comme Karl Marx ou encore Theodor W. Adorno. À ce propos, à l'occasion du premier numéro de la revue, il y a vingt ans, son fondateur, Jean-Marie Vincent, avait indiqué :

«Variations entend bien réagir contre ceux qui jettent Marx aux orties, et avec lui les questions qu'il a posées. La revue prendre au contraire Marx au sérieux, suffisamment pour dialoguer avec lui en le critiquant, tout cela pour le prolonger au-delà de ce qu'il a pu dire. »

Tandis que vient de paraître la publication en français d'un dialogue entre Horkheimer et Adorno qui avait eu, en 1956 l'ambition de proposer, justement, " Nouveau manifeste » nous comptons bien poursuivre cet élan initial.

Dans le dialogue d'Adorno et Horkheimer, deux affirmations d'Adorno ne sont pas passé inaperçues des scrutateurs et commentateurs de tout bord. En effet, après avoir posé que ce manifeste dont les auteurs avaient le projet devait être un "Manifeste strictement léniniste", le philosophe indique avoir «toujours voulu essayer de rejoindre une théorie qui est fidèle à Marx, Engels et Lénine, mais qui, d'un autre côté, ne retombe pas en-deçà de la culture la plus avancée ». Chris Cutrone a ainsi tenté, à partir de là, de retrouver les traces d'un « léninisme adornien ». Cela a donné lieu à un débat faisant intervenir également Andrew Feenberg et Richard Westerman que les quatre premiers articles de ce numéro - qui en constituent une première partie retracent, précédés d'une présentation de leur traducteur, David Buxton. 
Deux textes d'anthologie des co-fondateurs de l'Institut de Francfort en 1923, Max Horkheimer et Karl Korsch, exhumés et traduits par Alexander Neumann, viennent ensuite troubler les lectures conventionnelles. L'un date de 1931 et discute directement la philosophie de Lénine, à qui il reproche sa limitation métaphysique peu concrète et anhistorique. L'autre expose les apories du marxisme en 1950, d'un point de vue qui se veut révolutionnaire. À la suite, Neumann signale sa propre lecture théoriquehistorique de ce développement. Une tentative d'actualisation qui se trouve encore amplifiée par les vues qu'expose Vladimir Safatle, depuis le Brésil, sur l'usage de la Théorie critique et l'état la gauche, interrogé par un collectif composé de Bruna Coelho, Marília Mello Pisani, Felipe Ribeiro, Fernanda Azeredo et traduit par Daphné Anton.

C'est dans le cadre de telles recherches nouvelles sur les écrits de Marx qu'Adorno a donné le fameux "séminaire de 1962 » qui nous est parvenu grâce aux notes qu'y a prises Hans Georg Backhaus, et qui ont été publiées pour la première fois à la fin de son ouvrage Dialektik der Wertform. Dans ce texte, à la traduction duquel se sont attelés David Buxton, Alexander Neumann et Christophe Magis, Adorno pose une question fondamentale, quoiqu'irrésolue, concernant rôle de l'échange marchand (qui est une pratique et non pas une simple abstraction). Le philosophe examinera ensuite plus précisément ce rôle en 1965, dans un débat direct - et méconnu - avec Alfred SohnRethel. Les notes manuscrites d'Adorno, à propos de l'abstraction de l'échange sont ici rendues en français par Alexander Neumann. Un chapitre de Jean-Marie Vincent, qui s'inscrit dans le sillage de cette réception, vient compléter la compréhension, concernant le fétiche de la marchandise et son empire (1987).

7 Puis deux autres articles viennent encore élargir la réflexion. Le premier, signé Christophe Magis, s'attache à analyser les rapports d'Adorno au concept d'idéologie dans le cadre de son travail sur la culture de masse. Magis s'interroge sur la manière dont ce concept marxien résonne dans la catégorie d'industrie culturelle. Last but not least, Susan Buck-Morss, s'intéresse à la question de l'analyse de l'art dans une perspective benjaminienne "antistalinienne " dans le dernier texte de ce dossier, traduit par David Buxton et Christophe Magis.

Deux textes en hors-champ complètent ce beau numéro, qui ouvrent, chacun à leur manière, une réflexion critique sur le contrôle, le travail et les machines, dans une perspective articulant Marx, Deleuze et la Théorie critique.

Bonnes lectures déconfinées! 